\title{
The studies of the effect of sulfates added as chromium(VI) reducers in portland cement
}

\author{
Wiesława Nocuń-Wczelik • Paulina Golonka • \\ Grzegorz Malata
}

Received: 15 January 2014 / Accepted: 29 June 2014/Published online: 23 July 2014

(c) The Author(s) 2014. This article is published with open access at Springerlink.com

\begin{abstract}
The calorimetric measurements were applied in testing the effect of some sulfates, used as $\mathrm{Cr}(\mathrm{VI})$ reducers in cement, as setting and hardening modifiers. The iron(II) sulfate is most commonly added as $\mathrm{Cr}$ reducer to cement on grinding. This was taken as a reference in the studies of the other potential chromium reducers, such as tin(II) and manganese(II) sulfates on cement hydration. The high percentage of admixtures was reduced steadily from very high overdosage- to find the possible effect of nonhomogeneity resulted from the hygroscopic character of compounds used and to detect the possible products which can be formed-to relatively small quantity, as used in practice. The progress of cement hydration was investigated by calorimetry and chemical shrinkage measurements. The rheological properties of cement paste admixtured with iron, tin, and manganese sulfates were investigated, as well as the phase composition of hydrated pastes was studies by XRD. The compressive strength of the small paste cylinders was measured. Finally, the hydrated samples were subjected to the SEM observations. The tin sulfate showed the strongest retarding action as it was proved by calorimetry and chemical shrinkage data, as well as by strength and rheological measurements; however, at small quantities, this compound has a positive impact on setting and hardening. The detrimental effect of overdosed $\mathrm{Mn}$ and $\mathrm{Fe}$ sulfates due first of all to the formation of higher amount of ettringite at very early age was found. This can be proved additionally by the change of rheological parameters-higher yield stress and viscosity.
\end{abstract}

W. Nocun-Wczelik ( $\square) \cdot$ P. Golonka · G. Malata Department of Building Materials Technology, Faculty of Materials Science and Ceramics, University of Science and Technology AGH, al. Mickiewicza 30, 30-059 Kraków, Poland e-mail: wiesia@agh.edu.pl
Keywords Calorimetry - Chemical shrinkage · Compressive strength · Iron(II), tin(II), manganese(II) sulfates $\cdot$ Hydration $\cdot$ Rheology

\section{Introduction}

The reduction of $\mathrm{Cr}(\mathrm{VI})$ to $\mathrm{Cr}(\mathrm{III})$ in cement is required in order to limit the chromium(VI) content in the leachate below $2 \mathrm{ppm}$, according to the EC Directive [1]. This can be the done by the addition of approximately $0.3 \%$ iron(II) sulfate to cement [2-4]. The reduction of $\mathrm{Cr}(\mathrm{VI})$ can be also done using tin, antimony, or manganese(II) sulfates as well. There are many compositions with sulfate-based $\mathrm{Cr}(\mathrm{VI})$ reducing agent and the other compounds patented $[5,6]$.

The iron sulfate is the most popular, available, and economical $\mathrm{Cr}(\mathrm{VI})$ reducer, but it reveals lower effectiveness as compared to the latter ones [2,3]. A highly hygroscopic $\mathrm{FeSO}_{4}$, added in an excess, reveals very often an inhomogeneity of distribution. Then, the brown stains can appear on the surface of concrete elements (pavement blocks, decorative elevation plates), while the other admixtures have no coloring effect, as it appeared in our previous experiments [7].

The problem of $\mathrm{Cr}$ reducers is discussed mainly from the effectiveness, economy, handling methods, and reduction mechanism point of view [2, 6]. However, the reducers used are not without influence on the properties of hydrating cement paste despite of their low content. Setting and hardening process can be somewhat altered due to the presence of heavy metals and sulfate ions because of the interaction with hydrating paste. The phenomena occurring during the hydration in the presence of the excess of reducer (as it is in industrial practice), added to guarantee the complete reduction, or when the 
Table 1 Chemical composition of CEM I 42,5R cement

\begin{tabular}{lllllllllll}
\hline Component & $\mathrm{SiO}_{2}$ & $\mathrm{Al}_{2} \mathrm{O}_{3}$ & $\mathrm{Fe}_{2} \mathrm{O}_{3}$ & $\mathrm{CaO}$ & $\mathrm{MgO}$ & $\mathrm{SO}_{3}$ & $\mathrm{Na}_{2} \mathrm{O}$ & $\mathrm{K}_{2} \mathrm{O}$ & L.O.I. & Total \\
\hline \% By mas. & 19.2 & 5.1 & 2.9 & 61.8 & 1.5 & 3.52 & 0.18 & 0.96 & 2.8 & 97.88 \\
\hline
\end{tabular}

Fig. 1 Heat of hardening curves for cement pastes produced from CEM I 42,5R $(\mathrm{w} / \mathrm{c}=0.5)$

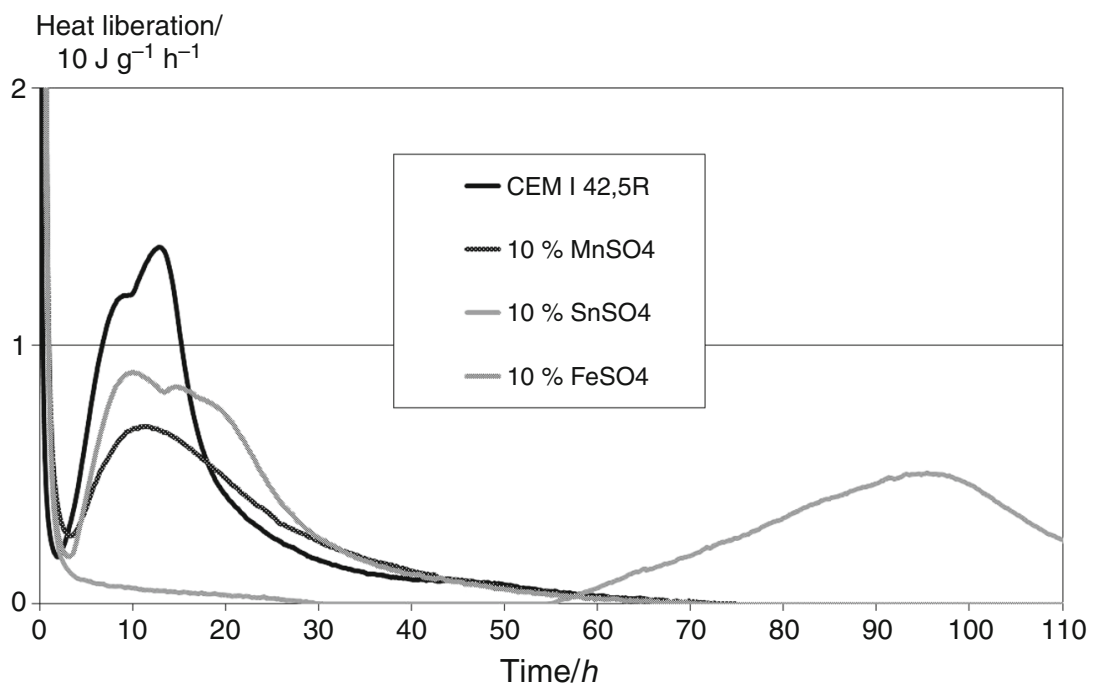

reducer is not homogeneously distributed and hygroscopic, are strongly related to those occurring as the solidification of hazardous wastes (with heavy metal compounds) or sulfate attack takes place. Therefore, they can be considered and discussed based on the relevant reports (e.g., [8-10]). Additions of more or less amphoteric metals containing salts are expected to hydrolyze and form, in highly basic environment, some new basic salts of $\mathrm{Ca}$ or to separate as hydroxides (e.g., [8, 11]). This was investigated for example by Hill and Sharp [11] in case of tin compounds.

The calorimetric measurements appeared again as a convenient, rapid first method of the hydrating systems assessment, as used in case of additives/admixtures, and different modifying agents for a couple of years [12-18]. They were taken as a starting point, and subsequently the chemical shrinkage, phase composition, microstructure, and rheological properties were investigated. The effect of sulfates on the compressive strength of small samples was also determined.

\section{Experimental}

\section{Materials}

The portland cement CEM I class 42,5R was used; chemical composition of cement is given in Table 1. The commercially available iron(II), tin(II), and manganese(II) sulfates of analytical purity were used as admixtures, added from 0.1 to $10 \%$ by mass of cement. $1 \%$ of iron or manganese sulfate corresponds to $17.5 \mathrm{mmol} / \mathrm{l}$ (at $\mathrm{w} / \mathrm{c}=0.4)$ and $1 \%$ of tin sulfate corresponds to $12.2 \mathrm{mmol} / 1$, respectively.

Methods

The heat of hardening was measured in the non-isothermalnon-adiabatic microcalorimeter (of our own laboratory construction, from commercially available elements, equipped with computer controlled registration and data refinement) on the pastes produced from $20 \mathrm{~g}$ cement samples at $\mathrm{w} / \mathrm{c}=0.5$. The starting temperature was $25^{\circ} \mathrm{C}$. The example set of heat evolution curves is given in Figs. 1 and 2.

Chemical shrinkage was determined according to ASTM C 1608-1607 standard. This is based on the measurements of the loss of water in the capillary placed above the surface of the paste (produced at water to cement ratio 0.4 , as recommended in the standard) sealed in a cylindrical container, due to the absorption of water by cement paste to avoid self-drying. The pastes were placed in polystyrene cylinders with $28 \mathrm{~mm}$ diameter and $54 \mathrm{~mm}$ height (instead of the glass cylindrical containers with $22 \mathrm{~mm}$ diameter and $55 \mathrm{~mm}$ height-recommended in the standard). The chemical shrinkage was measured in cement pastes produced from CEM I at different percentages of admixtures. The example results are shown in Figs. 3 and 4. 
Fig. 2 Heat of hardening curves for cement pastes produced from CEM I 42,5R $(\mathrm{w} / \mathrm{c}=0.5)$

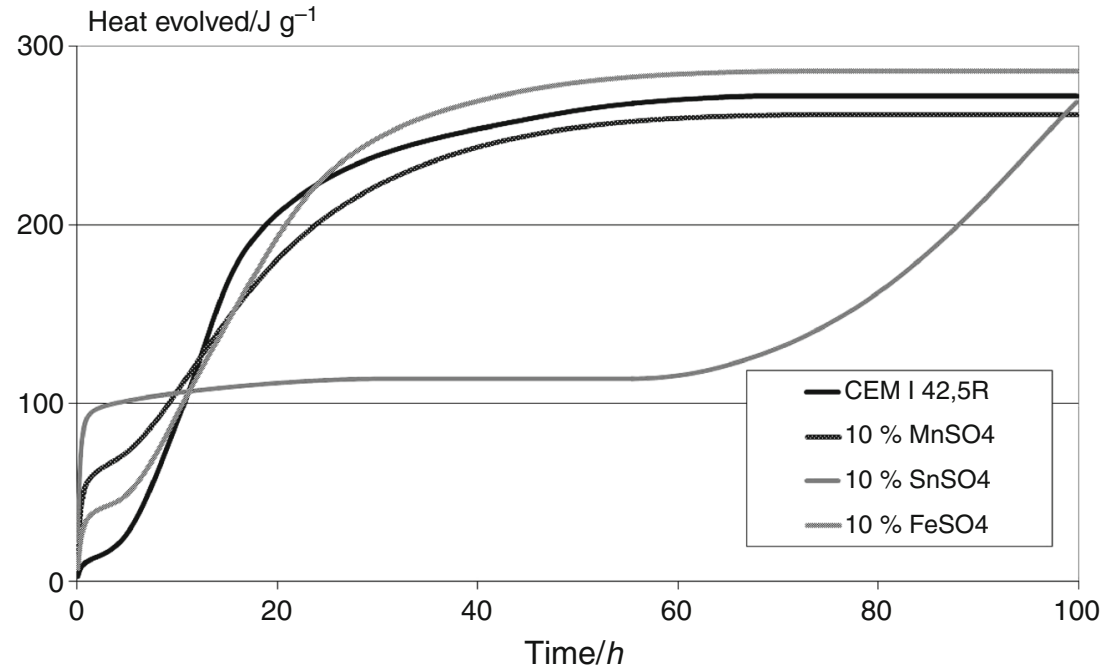

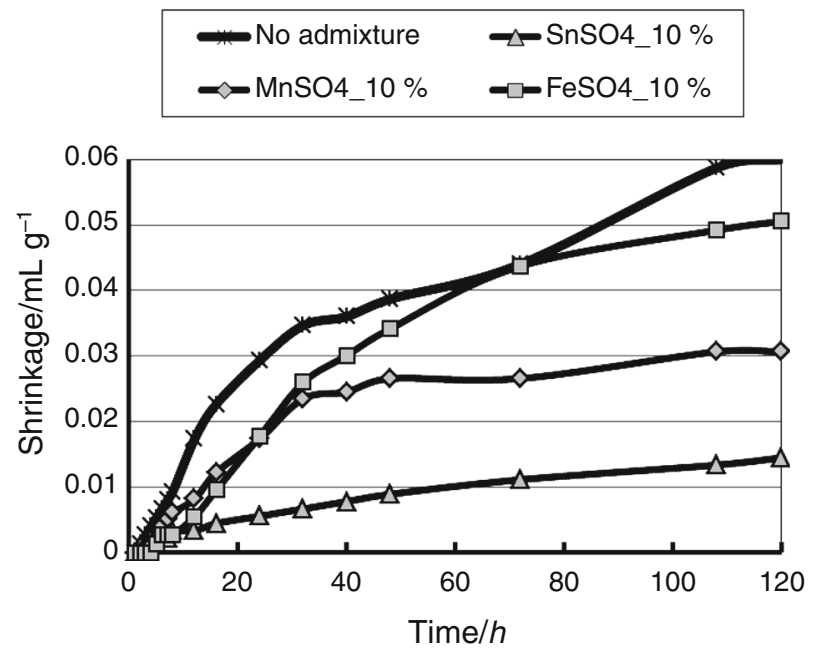

Fig. 3 Chemical shrinkage of pastes produced with $\mathrm{SnSO}_{4}, \mathrm{FeSO}_{4}$, and $\mathrm{MnSO}_{4}$ admixtures $(\mathrm{w} / \mathrm{c}=0.4)$

Rheological studies were done with help of rotational rheometer. The flow curves for cement pastes doped with 1 and $5 \%$ admixture (by mass of cement) $\mathrm{w} / \mathrm{c}=0.4$ (this w/c ratio, lower than used in calorimetric measurements allows to avoid segregation in the paste subjected to the continuous rotation between the cylinders), at increasing and decreasing shear rates, were produced, and the relationship between the shear stress and shear rate is plotted in Fig. $5\left(\tau_{\mathrm{r}}=f\left(D_{\mathrm{r}}\right)\right.$.

The measurements of electrical conductivity of hydrating cement suspensions were performed using a laboratory equipment consisting of waterproof conductivity meter, conductivity sensor, thermometer, and magnetic stirrer. Cement suspensions $(\mathrm{w} / \mathrm{c}=100)$ were doped with $5 \%$ $\mathrm{Cr}(\mathrm{VI})$ reducing admixtures (by mass of cement). The results are presented in Fig. 6.

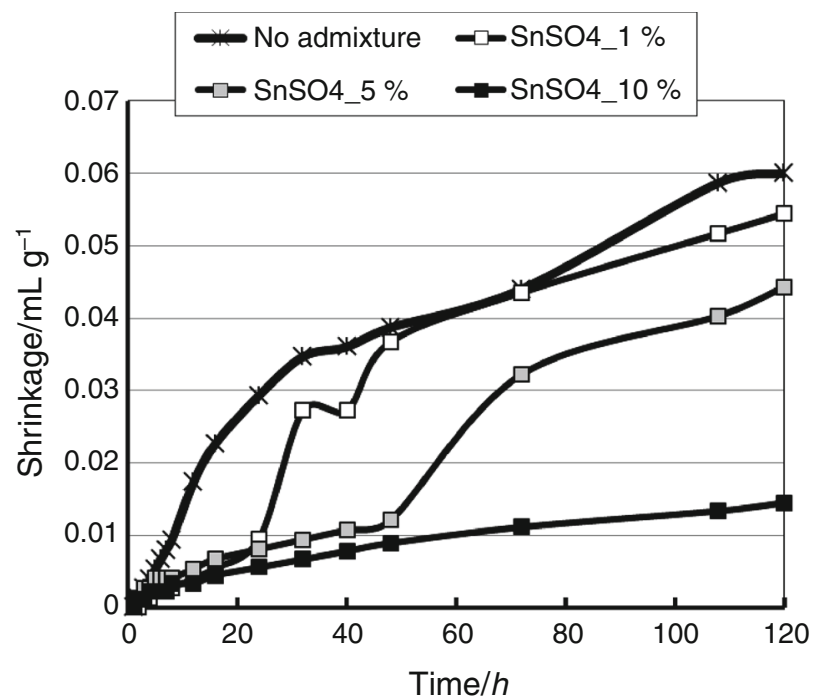

Fig. 4 Chemical shrinkage of pastes produced with $\mathrm{SnSO}_{4}$ admixture $(\mathrm{w} / \mathrm{c}=0.4)$

The compressive strength was measured on cement pastes $(\mathrm{w} / \mathrm{c}=0.4$, not 0.5 because of the possible sedimentation in case of retarded hydration in admixtured samples) after 2, 7, and 28-day curing. Small cylindrical samples with diameter $32 \mathrm{~mm}$ and height $42 \mathrm{~mm}$ were stored in standard conditions according to EN 196-1. The admixtures were added as 1,5 , and $10 \%$ by mass of cement. The results are presented in Table 2 .

The phase composition was studied by XRD for the $24 \mathrm{~h}$ hydrated pastes with $\mathrm{Cr}(\mathrm{VI})$ reducers added as $5 \%$ by mass of cement (Fig. 7) $(\mathrm{w} / \mathrm{c}=0.5)$. The hydration process was stopped using acetone. The microstructure of fractured samples after $24 \mathrm{~h}$ hydration was observed under the scanning electron microscope. The particular phases were indentified and analyzed based on the EDS (the 


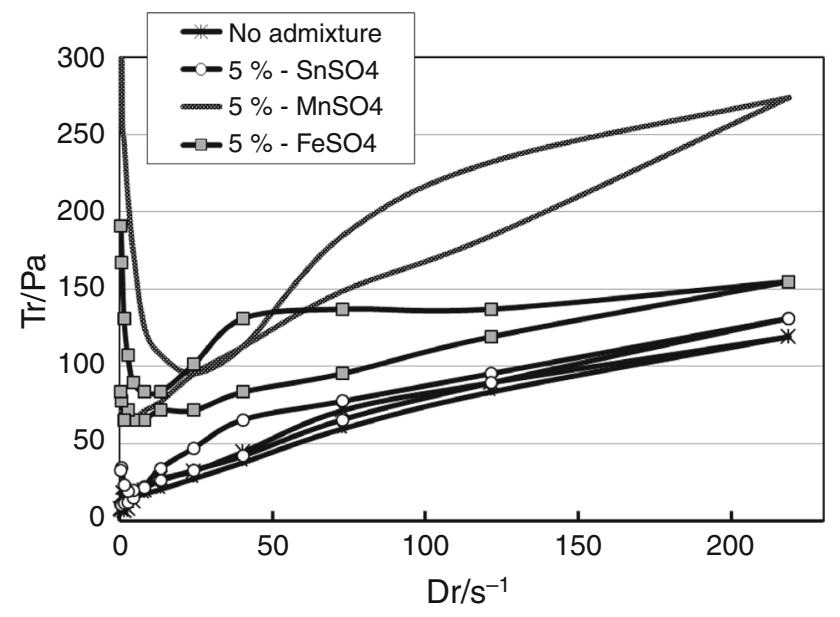

Fig. 5 Flow curves of cement pastes with $5 \%$ admixtures $(\mathrm{w} / \mathrm{c}=0.4)$
Table 2 Compressive strength of cement paste small cylindrical samples $(\mathrm{w} / \mathrm{c}=0.4)$

\begin{tabular}{lllll}
\hline Admixture & $\begin{array}{l}\text { Percentage by mass of } \\
\text { cement/\% }\end{array}$ & \multicolumn{3}{l}{$\begin{array}{l}\text { Compressive strength, } \\
\text { MPa }\end{array}$} \\
\cline { 3 - 5 } & & 2 days & 7 days & 28 days \\
\hline- & - & 29.1 & 41.3 & 53.0 \\
$\mathrm{FeSO}_{4}$ & 1 & 21.7 & 44.1 & 56.0 \\
& 5 & 16.5 & 34.3 & 43.9 \\
& 10 & 8.0 & 17.7 & 22.0 \\
$\mathrm{MnSO}_{4}$ & 1 & 27.9 & 43.6 & 60.4 \\
& 5 & 18.6 & 36.3 & 55.1 \\
& 10 & 14.1 & 24.2 & 32.6 \\
$\mathrm{SnSO}_{4}^{\mathrm{a}}$ & 1 & 15.3 & 41.3 & 57.1 \\
\hline
\end{tabular}

${ }^{a}$ The samples with 5 and $10 \%$ additives are not hardened after 2 days
Fig. 6 Conductivity of cement suspensions processed with admixtures added as $5 \%$ by mass of cement $(\mathrm{w} / \mathrm{c}=100)$

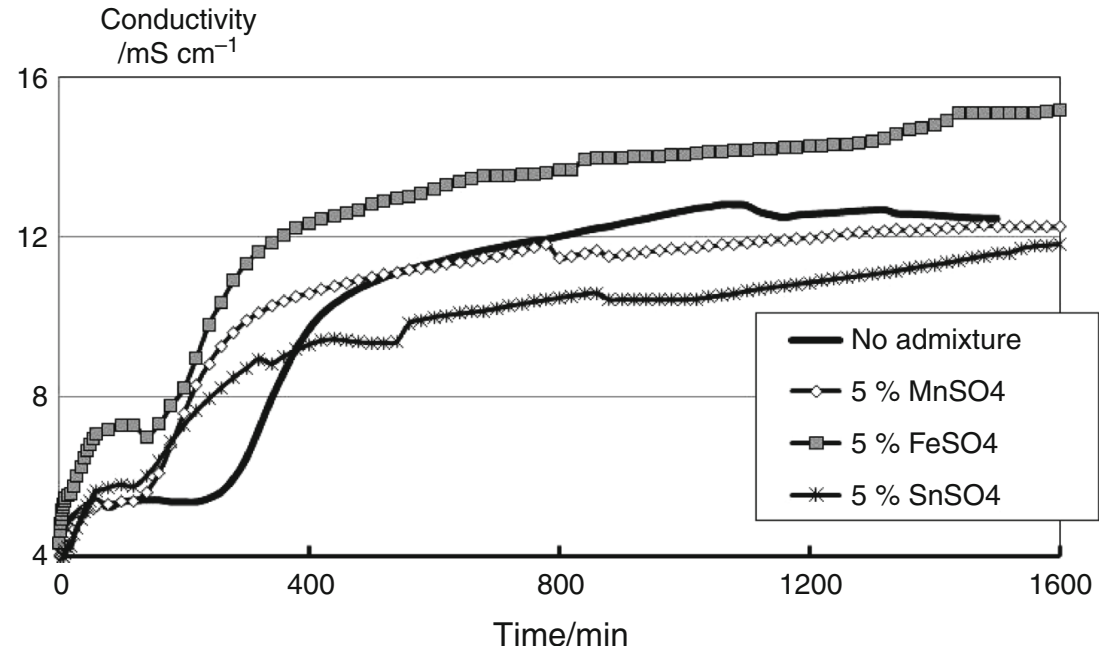

descriptions under the SEM illustrations). The results are shown as Figs. 8, 9, 10, and 11.

Results and discussion

\section{Calorimetry}

The example calorimetric results are presented as $\mathrm{d} Q /$ $\mathrm{d} t=f(t)$ and $Q=f(t)$ plots in Figs. 1 and 2, for the pastes hydrated with the highest admixture content. The early hydration followed by calorimetry is more or less hindered in the presence of sulfates during the first few hours of early hydration, as one can conclude from the lowering of heat evolution peak (Fig. 1). However, in case of Fe and Mn sulfates, the total heat evolved after approximately $8-10 \mathrm{~h}$ is almost equal to the value for reference. On the other hand, at the presence of tin sulfate, a serious retarding action is evident, and the significant elongation of induction period, up to over $50 \mathrm{~h}$, is observed at $10 \%$ (Fig. 1). After this period of time, the hindering effect of tin sulfate seems to be compensated by the renewed hydration (see Fig. 2). These results match very well with those previously reported $[11,12]$.

As one could find from Fig. 1, in the presence up to $10 \%$ manganese and iron sulfates, the induction period is short and not specially "profound". It means that these admixtures affect the intense hydrolysis of cement and simultaneously the precipitation of products when added in higher amount; they do not slow down significantly the hydration process as a whole-the maximum of the main heat evolution peak is specially shifted. The heat evolved value (Fig. 2) after $10 \mathrm{~h}$ is similar and do not differ specially at later age. However, the retardation in the presence of tin sulfate is accompanied by relevant reduction of total 
Fig. 7 XRD pattern of $24 \mathrm{~h}$ hydrated cement samples admixtured with $5 \% \mathrm{FeSO}_{4}$, $\mathrm{MnSO}_{4}$, and $\mathrm{SnSO}_{4}$ (w/ $\mathrm{c}=0.4)$; abbreviations: $G$ gypsum, Ett ettringite, $\mathrm{CH}$ calcium hydroxide

Fig. 8 Microstructure of reference cement paste with no admixture. See rather poorly developed hydration products at lower and higher magnification
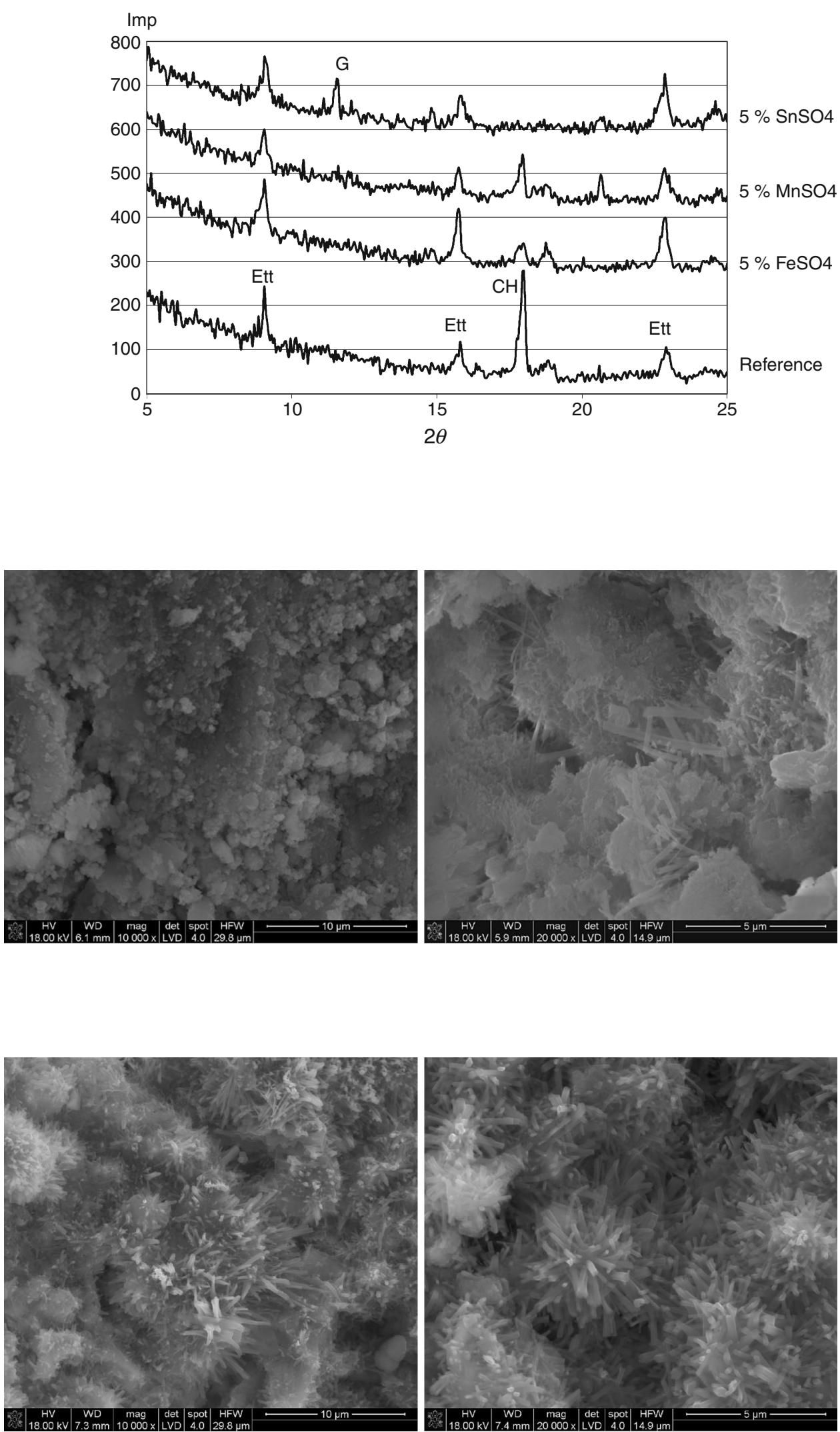

Fig. 9 Ettringite needles in cement paste with $5 \% \mathrm{FeSO}_{4}$ admixture 
Fig. 10 Microstructure of cement paste with $5 \% \mathrm{MnSO}_{4}$ admixture. The area enriched with $\mathrm{Mn}$ and $\mathrm{S}$ surrounded by $\mathrm{C}-\mathrm{S}-\mathrm{H}$ (on the left); the well developed forms of gypsum (on the right) and portlandite surrounded by $\mathrm{C}-\mathrm{S}-\mathrm{H}$
Fig. 11 Microstructure of cement paste with $5 \% \mathrm{SnSO}_{4}$ admixture; see the plate-like forms of gypsum surrounded by $\mathrm{C}-\mathrm{S}-\mathrm{H}$ (on the left) and platelike forms of $\mathrm{Ca}-\mathrm{Sn}$ hydroxide and portlandite (the presence of Sn was detected by EDS)
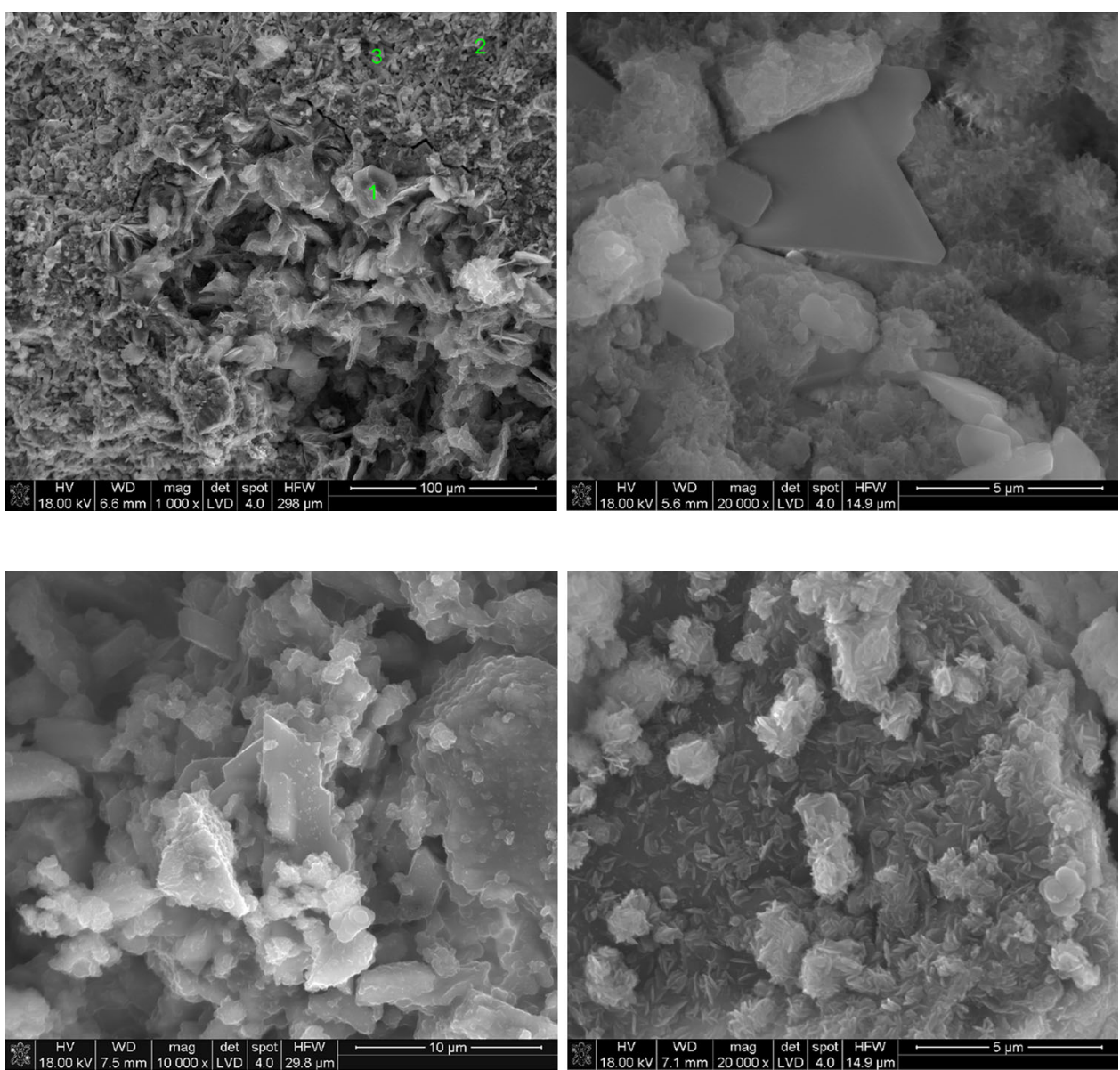

heat evolved at early age. The values close to those for reference are attained after a time when the maximum of second peak for the paste admixtured with tin sulfate appears (see Figs. 1 and 2).

\section{Chemical shrinkage}

The reference curve (Figs. 3 and 4) for cement paste with no admixture has typical shape with continuous, almost linear growth during the first $30 \mathrm{~h}$ up to the level about $0.03 \mathrm{~mL} \mathrm{~g}^{-1}$ of cement and subsequent slower growth leading to the amount of consumed water about $0.06 \mathrm{~mL} \mathrm{~g}^{-1}$ of cement after $120 \mathrm{~h} . \mathrm{MnSO}_{4}$ and particularly $\mathrm{SnSO}_{4}$ admixtures bring about considerable changes of chemical shrinkage. However, the differences between the shrinkage at very early age, up to $3-5 \mathrm{~h}$, are not high, in the range of ca. 0.001-0.003 $\mathrm{mL} \mathrm{g}^{-1}$ (Fig. 3). A significant increase of chemical shrinkage is subsequently observed in case of $10 \% \mathrm{MnSO}_{4}$ and $\mathrm{FeSO}_{4}$ up to $30 \mathrm{~h}$. However, the values for reference are higher than for the samples admixtured with sulfates.

At later age, the shrinkage values of pastes with higher contents of $\mathrm{Cr}(\mathrm{VI})$ reducers grow much slower. In the case of $10 \% \mathrm{SnSO}_{4}$, the shrinkage changes are the lowest and do not exceed $0.015 \mathrm{~mL} \mathrm{~g}^{-1}$; it means that the hydration process is slowed down markedly, and the sample does not accept the additional water.

The break down of shrinkage curves after the initial growth can be attributed to the change of diffusion rate through the layer of products formed on the grains. This diffusion barrier is presumably due to the formation of hydration products and can be strengthened in the presence of high amount of ettringite and/or basic salts covering the surface. In case of 1 and $5 \% \mathrm{SnSO}_{4}$, the shrinkage increases at later age, and it seems that "the barrier" is disrupted at some lower admixture concentration due to the processes occurring inside it, as it is illustrated in Fig. 4.

\section{Rheological measurements}

One can notice that the reference paste produced from cement at $\mathrm{w} / \mathrm{c}=0.4$ shows low yield stress and plastic viscosity (Fig. 5). An increase of the yield stress and plastic viscosity, as a result of introducing first of all the manganese sulfate-potentially strengthening the week 
structure of paste by the early hydration products formation-is clearly visible (lower curves in Fig. 5).

At $5 \%$ admixture content (by mass of cement, paste produced at $\mathrm{w} / \mathrm{c}=0.4)$, the reference flow curve, in comparison with the plots for the pastes modified with sulfates, is close to the Bingham model (very narrow hysteresis loop, see Fig. 5). The hysteresis loop is broadened with the structure forming effect, particularly in the case of $\mathrm{MnSO}_{4}$ and $\mathrm{FeSO}_{4}$. The effect of tin sulfate is much less pronounced; the flow curve at $5 \% \mathrm{SnSO}_{4}$ is similar to the reference.

\section{Conductometric measurements}

In the case of hydrating cement suspensions produced from neat cement, the conductometric measurements reveal, after an initial growth, something like an "induction period" up to almost 5 h (Fig. 6). This "induction period" is shortened in sulfate solutions to ca. $2 \mathrm{~h}$. Subsequently, more evident growth of conductivity is observed. In the suspension with no admixture, a maximum point appears after about 17-18 h, followed by a little lower conductivity.

The hydration in very diluted sulfate solutions gives practically no conductivity change at the starting point when cement is mixed into the stirred liquid. In the sulfate solutions, the conductivity shows no maximum value at later age - a slow increase up to over 1 day is observed. The conductivity of cement water suspension with $\mathrm{MnSO}_{4}$ shows shorter induction period and similar values as reference at later age. The conductivity of $\mathrm{FeSO}_{4}$ containing suspension is generally higher, while the values measured for cement hydrating in $\mathrm{SnSO}_{4}$ solution become the lowest after 7-8 h. It seems that the precipitation of hydration products in these four suspensions occurs in some other way. Presumably, the processes in diluted systems $(\mathrm{w} / \mathrm{c}=100)$ are less affected by the reactions occurring on the surface of cement grain in contact with the concentrated liquid phase (it means the deposition of products on the surface which is "natural" nucleation site), but they are rather controlled by solubility parameters of potential products.

\section{Phase composition}

From the XRD patterns of pastes with and without admixtures, one can find that the pastes produced from CEM I 42,5 $\mathrm{R}$ with $\mathrm{FeSO}_{4}, \mathrm{SnSO}_{4}$, and $\mathrm{MnSO}_{4}$ exhibit lower amount of $\mathrm{Ca}(\mathrm{OH})_{2}$ with increasing ettringite content. Furthermore, there is more unhydrated calcium silicates in cement pastes doped with sulfates. The ettringite is particularly noticeable in the sample admixtured with iron sulfate, poor in calcium hydroxide (see Fig. 7 as an example). The paste processed with $\mathrm{SnSO}_{4}$ solution shows practically no $\mathrm{Ca}(\mathrm{OH})_{2}$. In this paste, a significant amount of gypsum is produced, apart from ettringite.

\section{Compressive strength}

As one can see, in the presence of Fe and Mn sulfates added to cement pastes in amount exceeding $1 \%$ by mass of cement, the compressive strength generally decreases as compared to the control sample with no admixture. In case of $\mathrm{SnSO}_{4}$, the pastes with 5 and $10 \%$ admixture setting process are strongly retarded, and the segregation bleeding is observed; therefore, the samples are not susceptible to the compressive strength tests. However, at $1 \% \mathrm{Fe}, \mathrm{Mn}$, and $\mathrm{Sn}$ sulfate in the pastes, the compressive strength increases after 7 days curing as well as at later age is observed; for $\mathrm{MnSO}_{4}$ admixture, the values are the highest.

\section{Microstructure}

The reference paste shows, after 1 day hydration, a typical microstructure with more or less developed $\mathrm{C}-\mathrm{S}-\mathrm{H}$ and portlandite together with ettringite in the pores (see Fig. 8).

The paste doped with $\mathrm{FeSO}_{4}$ is dominated by elongated ettringite crystals (needles or laths) growing from cement grains to the space between them, as it can be observed under SEM (Fig. 9).

On the SEM images of $\mathrm{MnSO}_{4}$ doped paste, the ettringite crystals are not so well developed and spread out. The EDS analysis reveals the presence of strong $\mathrm{Ca}$ and $\mathrm{Si}$ bands with $\mathrm{Al}$ and $\mathrm{S}$ in the areas attributed structurally to the $\mathrm{C}-\mathrm{S}-\mathrm{H}$. This is presumably the mixture of $\mathrm{C}-\mathrm{S}-\mathrm{H}$ with ettringite phase; the gypsum crystals are well visible too (Fig. 10 right foto); the poorly developed areas enriched in $\mathrm{Mn}$ are also found. In the $\mathrm{SnSO}_{4}$ doped paste, the assemblages of platelike $\mathrm{Ca}-\mathrm{Sn}$ containing compound, poorly developed $\mathrm{C}-\mathrm{S}-\mathrm{H}$ and gypsum can be detected (Fig. 11). The formation of $\mathrm{Ca}-$ Sn hydroxide was reported earlier by Hill and Sharp [11].

\section{Conclusions}

The following concluding remarks can be drawn directly or indirectly from the results presented above:

- The Fe, Mn, and Sn sulfates present in amount higher than $1 \%$ by mass of cement in process water retard generally the hydration at early age, as determined by heat evolution studies, chemical shrinkage tests, XRD; the delay augments with concentration of admixture.

- The hindering action of $\mathrm{Sn}$ sulfate is particularly visible: hampered setting - the attempts to prepare the sample for strength tests failed; low values of rheological parameters, low chemical shrinkage, shortage of calcium hydroxide in hydrated paste.

- The formation of ettringite in the presence of additional sulfate ions is particularly well visible in case of $\mathrm{Fe}$ 
sulfate (XRD, SEM); the amount of ettringite in the presence of Mn or even Sn sulfate is almost the same.

- The rheological behavior is strongly affected by sulfate admixtures immediately after mixing with water-this is attributed to the presence of specific products formed in the pastes; the yield value and viscosity are particularly high in the case of Mn sulfate.

- The sulfate anions introduced additionally to the pastes take part in ettringite formation; in the case of $\mathrm{Sn}$ sulfate, the increased gypsum content is detected too.

- The role of particular accompanying cations viz. Fe, $\mathrm{Mn}$, and Sn is different. It seems that the tin sulfate acts as a strong retarder, while the hindering action of $\mathrm{Mn}$ or Fe sulfate is significantly less pronounced. This can be attributed to the phenomena relating to chemical equilibrium/hydrolysis and affect the dissolutionprecipitation of products occurring in the paste. As it could be proved experimentally, the most evident features are as follows: in the presence of Fe, the very well developed, long ettringite crystals are produced, in the presence of $\mathrm{Mn}$, the manganese hydroxide is formed, the $\mathrm{Sn}$ is present in $\mathrm{C}-\mathrm{S}-\mathrm{H}$, and the platelike forms of $\mathrm{Sn}-\mathrm{Ca}$ compounds are detected.

- The beneficial, strengthening effect of low admixture content as the compressive strength modifying agent should be underlined.

Open Access This article is distributed under the terms of the Creative Commons Attribution License which permits any use, distribution, and reproduction in any medium, provided the original author(s) and the source are credited.

\section{References}

1. European Parliament, Directive 2003/53/EC of the European parliament and of the council, official Journal of the European Union, 2003.

2. Hills LM, Johansen VCM. Hexavalent chromium in cement manufacturing: literature review, SN2983, Portland Cement Association, Skokie, Illinois, 2007.
3. Bensted J, The importance of $\mathrm{Cr}(\mathrm{VI})$ reducers in cements, Cement Wapno Beton, 2006;XI/LXXIII:29-35.

4. Klemm W. Hexavalent chromium in Portland cement. Cem Concr Aggr. 1994;16:43-7.

5. Magistri M, D'Arcangelo P. New reducing agent for cement. ZKG Int. 2008;3:61-5.

6. Erdem E, Donat R, Esen K, Tunç T. Removal of soluble Cr(VI) in cements by ferrous sulphate monohydrate, solid lignin and other materials. Ceram-Silikáty. 2011;55:85-93.

7. Nocun-Wczelik W, Golonka P, Łój G. The effect of $\mathrm{Cr}(\mathrm{VI})$ reducers on the concentration of soluble $\mathrm{Cr}$ and color of cement based materials. Ceram mater. 2011;53:809-13 (in Polish).

8. Gineys N, Aouad G, Damidot D. Managing trace elements in Portland cement-Part I: interactions between cement paste and heavy metals added during mixing as soluble salts. Cem Concr Comp. 2010;32:563-70.

9. Gollop RS, Taylor HFW. Microstructural and microanalytical studies of sulfate attack. I. Ordinary portland cement paste. Cem Concr Res. 1992;22:1027-38.

10. Cheng Y, Wei S, Scrivener K. Mechanism of expansion of mortars immersed in sodium sulfate solutions. Cem Concr Res. 2013;43:105-11.

11. Hill J, Sharp JH. The hydration products of portland cement in the presence of tin(II) chloride. Cem Concr Res. 2003;33:121-4.

12. Nocun-Wczelik W, Malolepszy J. Application of calorimetry in studies of the immobilization of heavy metals in cementitious materials. Thermochim Acta. 1995;269(270):613-9.

13. Nocuń-Wczelik W, Pytel Z. Heat evolution in hydrated cementitious systems admixtured with different set controlling components. J Therm Anal Calorim. 2004;77:159-64.

14. Nocuń-Wczelik W, Trybalska B, Żugaj E. Application of calorimetry in evaluation the effect of carbonate additives on cement hydration. J Therm Anal Calorim. 2013;113:351-6.

15. Gawlicki M, Nocuń-Wczelik W, Bąk $€$. Calorimetry in the studies of cement hydration. Setting and hardening of portland cement-calcium aluminate cement mixtures. J Therm Anal Calor. 2010;100:571-6.

16. Siler P, Kratky J, De Belie N. Isothermal and solution calorimetry to assess the effect of superplasticizers and mineral admixtures on cement hydration. J Therm Anal Calorim. 2012;107:313-20.

17. Pacewska B, Nowacka M, Wilińska I, Kubissa W, Antonovich V. Studies on the influence of spent FCC catalyst on hydration of calcium aluminate cements at ambient temperature. J Thermal Anal Calorim. 2011;105:129-40.

18. Antonovich V, Aleknevich M, Keriene J, Pundiene I, Stonys R. Investigating the hydration of deflocculated calcium aluminate cement-based binder with catalyst waste. J Therm Anal Calorim. 2012;109:537-44. 